\title{
Comparative Cytogenetic Studies on Hoplerythrinus unitaeniatus Populations (Pisces, Erythrindae)
}

\author{
L. Giuliano-Caetano ${ }^{1, *}$, L. C. Jorge ${ }^{2}$, O. Moreira-Filho ${ }^{3}$ \\ and L. A. C. Bertollo ${ }^{3}$ \\ ${ }^{1}$ Departamento de Biologia Geral, Universidade Estadual de Londrina, Caixa Postal 6001, \\ 86051-970 Londrina PR, Brazil \\ ${ }^{2}$ Faculdad de Ciencias Veterinarias, Universidad National del Nordeste, Argentina \\ ${ }^{3}$ Departamento de Genética e Evoluçad, Universidade Federal de São Carlos, Brazil
}

Accepted November 13, 2000

\begin{abstract}
Summary Hoplerythrinus unitaeniatus fish from 5 different locations in South America were cytogenetically studied. Five populations from Corrientes (Argentina), Miranda (Mato Grosso do Sul State, Brazil), Porto Velho (Rondônia State, Brazil), Parque Estadual do Rio Doce (Minas Gerais State, Brazil) and from the Paramaribo region (Surinam) were analyzed. The specimens from Corrientes, Miranda and Porto Velho presented a diploid number equal to 48, all M-SM chromosomes, with a fundamental number (NF) equal to 96 . The specimen from Surinam had $2 n=48$ (46 M$\mathrm{SM}+2 \mathrm{~A}$ ) and $\mathrm{NF}=94$. The specimens from Parque Estadual do Rio Doce had $2 n=52$ (46 M$\mathrm{SM}+6 \mathrm{~A}$ ) and $\mathrm{NF}=98$. These structural and numerical chromosome variations among $H$. unitaeniatus populations suggest that Hoplerythrinus may not be a monotypic genus as presently thought.
\end{abstract}

Key words Pisces, Erythrinidae, Hoplerythrinus unitaeniatus, Population analyses, Karyotypic diversity.

Erythrinidae is a relatively small Neotropical freshwater fish family, with only 3 genera: Erythrinus Scopoli, 1777; Hoplerythrinus Gill, 1896 and Hoplias Gill, 1903 (Godoy 1975).

Hoplerythrinus is thought to be a monotypic genus represented by Hoplerythrinus unitaeniatus. This is a very resistant species, presenting a vascular-rich swim bladder, through which an additional air respiration probably occur (Azevedo and Gomes 1943). Hoplerythrinus unitaeniatus has also short gill filaments, with few secondary lamella, which results in a reduced gill area; these are probably some of the conditions that lead to an supplementary air respiration (Fernandes and Rantim 1984).

Due its adaptations this species has been of interest in different biological fields. However there are few chromosomal data. Some preliminary studies (Bertollo and Moreira-Filho 1981, Giuliano and Bertollo 1984) pointed the occurrence of a structural chromosome polymorphism in a $H$. unitaeniatus population from Manaus (Amazonas State, Brazil). This population was studied in detail by Giuliano-Caetano and Bertollo (1988), showing a constant diploid number equal to 48, with variations in the number of M-SM and ST-A chromosomes. This species presents several pericentromeric, interstitial or telomeric heterochromatic blocks (Giuliano-Caetano and Bertollo 1988), as well as multiple Ag-NORs (Bertollo 1996). The hypothesis of a karyotype like that of H. unitaeniatus to be closed to ancestral complement of the Characiformes fish was critically analyzed by Arefjev (1990).

In this paper, we present the available data on karyotype organization of several $H$. unitaeniatus populations, with emphasis in their structural and numerical variations.

* Corresponding author, e-mail: giuliano@uel.com.br 
Material and methods

Hoplerythrinus unitaeniatus from 5 distinct South American populations, including Surinam, Brazil and Argentina were cytogenetically studied. Table 1 shows the collection sites and the correspondent analyzed samples.

The specimens were injected with a $0.0025 \%$ colchicine solution, $1 \mathrm{ml} / 100 \mathrm{~g}$ of body weight, for $1 \mathrm{~h}$. The chromosome preparations were obtained from kidney cells by the "air drying" technique (Bertollo et al. 1978). The chromosomes were arranged in a decreasing order of size, and classified in 2 groups: meta-submetacentric (M-SM) and acrocentric (A). The fundamental number (NF) was calculated taking into account the A and the M-MS chromosomes with one and two arms, respectively.

\section{Results}

The specimens from Corrientes (Argentina), Miranda (Brazil) and Porto Velho (Brazil) showed $2 n=48$ chromosomes, all M-SM and therefore with a NF equal to 96 (Table 1, Fig. 1A, B, C). No chromosomal differences were found among males and females karyotypes.

The specimen from Paramaribo (Surinam) also had a diploid number equal to 48. However, the karyotype presented $46 \mathrm{M}-\mathrm{SM}+2 \mathrm{~A}$, and NF=94 (Table 1, Fig. 1D).

On the other hand, the specimens from Parque Estadual do Rio Doce (Brazil) were characterized by a distinct diploid number and karyotype structure, i.e., $2 n=52(46 \mathrm{M}-\mathrm{SM}+6 \mathrm{~A})$ and NF=98 (Table 1, Fig. 1E). Male and female karyotypes were also similar, without specific sex chromosomes.

\section{Discussion}

Among the Erythrinidae fish, the genus Hoplias has been the most cytogenetically studied. The H. lacerdae group shows a more conservative karyotype, with a constant $2 n=52$ chromosomes among the populations analyzed (Morelli 1998). On the other hand, the H. malabaricus group shows divergent karyotypes in different populations, with a diploid number ranging from $2 n=39$ to 42, and with distinct sex chromosome systems (Bertollo et al. 1986, 1997a, Bertollo and Mestriner

Table 1. Karyotypic characteristics for Hoplerythrinus unitaeniatus populations

\begin{tabular}{llllll}
\hline \multicolumn{1}{c}{ Location } & Sample & $2 n$ & NF & Karyotype & Ref. \\
\hline Manaus-AM & & $48(\mathrm{a})$ & 96 & $48 \mathrm{M}-\mathrm{SM}$ & 1 \\
Manaus-AM & $48(\mathrm{~b})$ & 94 & $46 \mathrm{M}-\mathrm{SM}+2 \mathrm{~A}(*)$ & 1 \\
Manaus-AM & & $48(\mathrm{c})$ & 94 & $46 \mathrm{M}-\mathrm{SM}+2 \mathrm{~A}(* *)$ & 1 \\
Manaus-AM & & $48(\mathrm{~d})$ & 95 & $47 \mathrm{M}-\mathrm{SM}+1 \mathrm{~A}$ & 1 \\
Aripuanã-MT & & 48 & 96 & $48 \mathrm{M}-\mathrm{SM}$ & 2 \\
Porto Velho-RO & $2 \mathrm{~F}+3 \mathrm{M}$ & 48 & 96 & $48 \mathrm{M}-\mathrm{SM}$ & 3 \\
Miranda-MS & $4 \mathrm{~F}+5 \mathrm{M}$ & 48 & 96 & $48 \mathrm{M}-\mathrm{SM}$ & 3 \\
Corrientes-Ar & $5 \mathrm{~F}+2 \mathrm{M}$ & 48 & 96 & $48 \mathrm{M}-\mathrm{SM}$ & 3 \\
Posadas-Ar & & 48 & 96 & $48 \mathrm{M}-\mathrm{SM}$ & 4 \\
Paramaribo-Su & 1F & 48 & 94 & $46 \mathrm{M}-\mathrm{SM}+2 \mathrm{~A}$ & 3 \\
P. E. Rio Doce-MG & 1F+1M & 52 & 98 & $46 \mathrm{M}-\mathrm{SM}+6 \mathrm{~A}$ & 3 \\
\hline
\end{tabular}

$2 n=$ diploid number, $\mathrm{NF}=$ fundamental number, $\mathrm{M}-\mathrm{SM}=$ meta- and submetacentric chromosomes; $\mathrm{A}=$ acrocentric chromosomes; AM, MT, RO, MS, MG=Brazilian states of Amazonas, Mato Grosso, Rondonia, Mato Grosso do Sul and Minas Gerais, respectively; $\mathrm{Ar}=$ Argentina; $\mathrm{Su}=$ Surinam; $(*)=$ acrocentric chromosomes with a similar size; $(* *)=$ acrocentric chromosomes with different size; $\mathrm{F}=$ female; $\mathrm{M}=$ male. References: 1. Giuliano-Caetano and Bertollo (1988); 2. GiulianoCaetano (1986); 3. Present study; 4. Bertollo, L. A. C. (unpublished). 


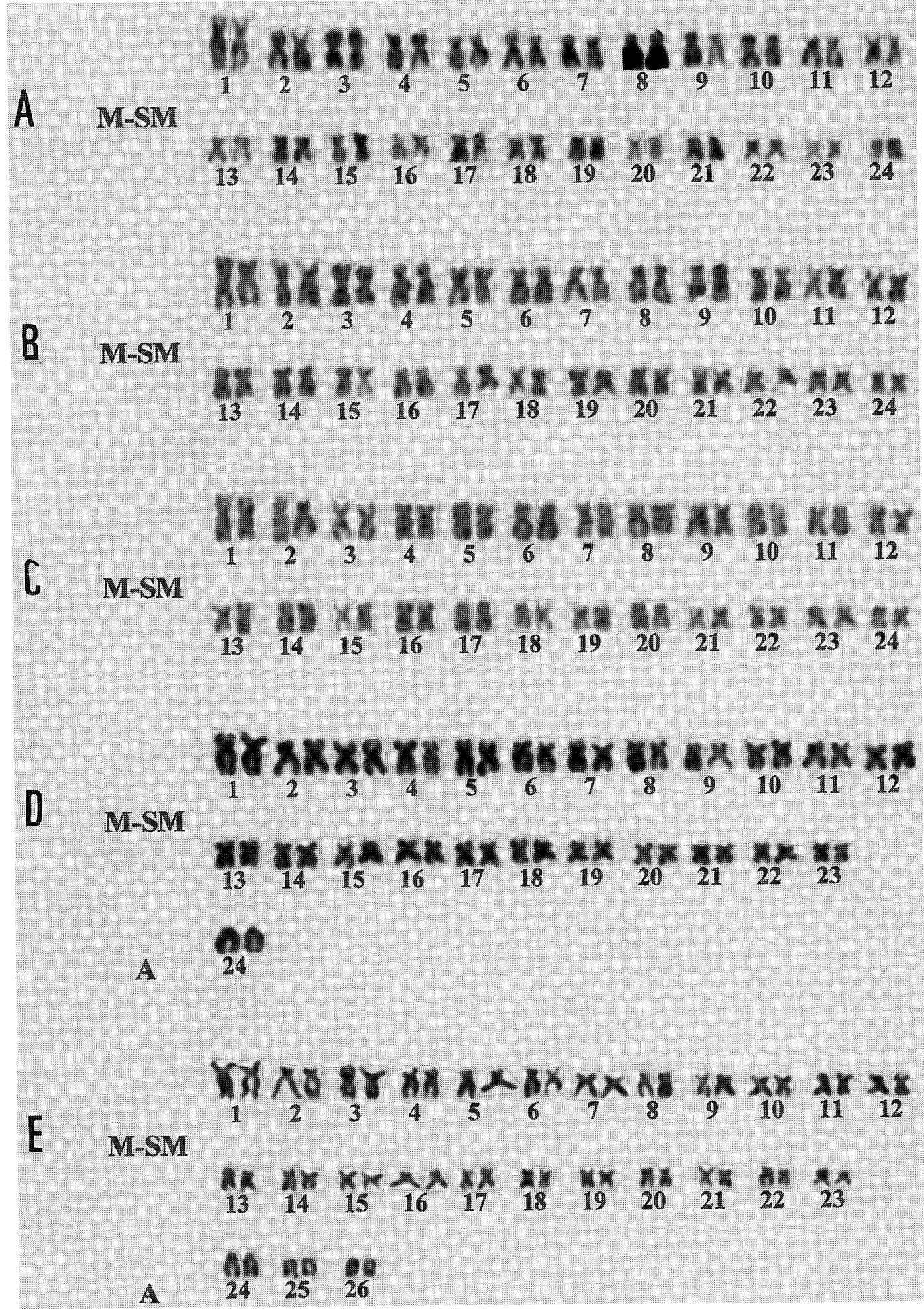

Fig. 1. Hoplerythrinus unitaeniatus karyotypes from different populations. A) Corrientes (Argentina), B) Miranda (Brazil), C) Porto Velho (Brazil), D) Paramaribo (Surinam), E) Parque Estadual do Rio Doce (Brazil). 
1998).

Earlier studies on Hoplerythrinus unitaeniatus from the rio Negro (Manaus, Amazonas State, Brazil) had shown 4 different cytotypes in this population (Table 1), characterized as cytotype a: $2 n=48$ (M-SM chromosomes), cytotype b: $2 n=48$ (46 M-SM+2 large A chromosomes), cytotype c: $2 n=48$ (46 M-SM+2 A chromosomes, one large and the other small sized) and cytotype d: $2 n=48$ ( $47 \mathrm{M}-\mathrm{SM}+1$ large A chromosome). Thus, this population presents a structural chromosome polymorphism probably due to pericentric inversions (Giuliano-Caetano and Bertollo 1988). Besides, a triploid specimen $(2 n=3 x=72)$ was also found in this same population (Giuliano-Caetano and Bertollo 1990). Specimens from the rio Aripuanã, (Aripuanã, Mato Grosso State, Brazil), are also characterized by a karyotype similar to that of cytotype a from Manaus (Giuliano-Caetano 1986).

The data so far obtained is summarized in Table 1, showing a typical karyotypic diversity in $H$. unitaeniatus populations. The populations from Corrientes (Argentina), Miranda (Brazil) and Porto Velho (Brazil) had a similar karyotypic structure, which also corresponds to that found in the populations from Posadas (Argentina), Aripuanã (Brazil) and Manaus cytotype a (Brazil), all showing $2 n=48 \mathrm{M}-\mathrm{SM}$ and NF$=96$. However, the populations from Paramaribo (Surinam) and the Parque Estadual do Rio Doce (Brazil) not only differ among each other but are also distinct from the other populations, concerning the diploid number and/or chromosomal formula. Although showing the same chromosomal number and NF (46 M-SM+2 A), the H. unitaeniatus karyotypes from Surinam and Manaus (cytotype b) differ in respect to the marker acrocentric chromosomes. Thus, this chromosome presents a small well visible short arm in the specimen from Surinam, which corresponds to a NOR location (Bertollo 1996). In the Manaus specimens, the acrocentric is also a NOR bearing chromosome but the NOR is located in a subterminal position on the long arm. Besides, a prominent interstitial heterochromatic block can be seen in this chromosome (Giuliano-Caetano and Bertollo 1988), which shows a more reduced size in the acrocentric chromosome from Surinam (Bertollo, unpublished data).

Only 4 populations have already been investigated concerning the nucleolar organizing regions, all presenting multiple NORs but with variations in the chromosomal locations. In synthesis, these regions were observed in an (1) interstitial position on metacentric chromosomes, (2) subterminal position on the long arm of acrocentric chromosomes, (3) terminal position on the short arm of acrocentric chromosomes, and (4) terminal position on the short arm of submetacentric chromosomes. The situations (1), (2) and (4) were observed in the Manaus population (Giuliano-Caetano 1986), (3) in the Parque Estadual do Rio Doce population (Giuliano-Caetano 1986), (1) and (3) in the Surinam population (Bertollo 1996) and (1) in the Posadas population (Bertollo 1996).

The overall data show that the chromosomal diversity among populations $(2 n=48, \mathrm{NF}=94$; $2 n=48, \mathrm{NF}=96 ; 2 n=52, \mathrm{NF}=98)$ results from rearrangements leading to structural and numerical variations. At first, it could be supposed that the wide distribution of the $2 n=48 \mathrm{M}-\mathrm{SM}$; NF=96 karyotype, from Amazonas State (Brazil) to Argentina, and including different river basins, could represent an ancestral condition in the species, compared to the other chromosomal forms with a more restrict distribution. On the other hand, the occurrence of a diploid number higher than $2 n=48$ in other Erythrinidae fish, as in Hoplias lacerdae, $2 n=50$ (Morelli 1998) and Erythrinus erythrinus, $2 n=52$ (Molina and Bertollo 1993) could also suggest an ancestral condition for the $2 n=52$; $\mathrm{NF}=98$ karyotype among the $H$. unitaeniatus fish. However, definitive conclusions are not possible for the moment. Future studies may detect new karyotypic forms, allowing a better understanding of the evolutionary history of this fish group.

As H. unitaeniatus is a widely distributed species, a certain differentiation degree could be occurring among distinct populations, as expressed by their chromosomal variations. In this sense, it is possible that Hoplerythrinus may not be a monotypic genus as presently thought. If so, the chromosomal data will be useful tools for a taxonomic revision of this fish group. 


\section{Acknowledgments}

This work was supported by Conselho Nacional de Desenvolvimento Científico e Tecnológico (CNPq). The authors are grateful to the Brazilian Embassy and to the Agriculture and Fishery Ministry in Surinam, and to Dr. Paulo Cesar Venere for their help in fish supplying.

\section{References}

Arefjev, V. A. 1990. Karyotypic diversity of characid families (Pisces, Characidae). Caryologia 43: 291-304.

Azevedo, P. and Gomes, A. L. 1943. Contribuição ao estudo da traíra Hoplias malabaricus (Bloch 1794). Bol. Indústria Animal 5: 15-64.

Bertollo, L. A. C. 1996. The nucleolar organizer regions of Erythrinidae fish. An uncommon situation in the genus Hoplias. Cytologia 61: 75-81.

- Fontes, M. S., Fenocchio, A. S. and Cano, J. 1997b. The $\mathrm{X}_{1} \mathrm{X}_{2} \mathrm{Y}$ sex chromosome system in the fish Hoplias malabaricus. I. G-, C- and chromosome replication banding. Chromosome Res. 5: 493-499.

— and Mestriner, C. A. 1998. The $\mathrm{X}_{1} \mathrm{X}_{2} \mathrm{Y}$ sex chromosome system in the fish Hoplias malabaricus. II. Meiotic analyses. Chromosome Res. 6: 141-147.

- and Moreira-Filho, O. 1981. Estudos citogenéticos em populaçöes do gênero Hoplerythrinus (Pisces, Erythrinidae). Ciênc. Cult. (Suppl.) 33: 695.

- - - and Fontes, M. S. 1997a. Karyotypic diversity and distribution in Hoplias malabaricus (Pisces, Erythrinidae). Cytotypes with $2 n=40$ chromosomes. Brazil. J. Genet. 20: 237-242.

- - - and Galetti Jr., P. M. 1986. Cytogenetics and taxonomy: considerations based on chromosome studies of freshwater fish. J. Fish Biol. 28: 153-159.

-, Takahashi, C. S. and Moreira-Filho, O. 1978. Cytotaxonomic considerations on Hoplias lacerdae (Pisces, Erythrinidae). Brazil. J. Genet. 1: 103-120.

Fernandes, M. N. and Rantim, F. T. 1984. Estudo morfofuncional comparativo das brânquias de três espécies da família Erythrinidae (Pisces, Teleostei): Hoplias malabaricus, Hoplias lacerdae e Hoplerythrinus unitaeniatus. Ciênc. Cult. 36: 608-609 (Abstracts).

Giuliano, L. and Bertollo, L. A. C. 1984. Variação cariotípica em Hoplerythrinus unitaeniatus (Pisces, Erythrinidae) de Manaus (AM). Ciênc. Cult. (Suppl.) 36: 863.

Giuliano-Caetano, L. 1986. Estudo citogenético em Hoplerythrinus unitaeniatus (Pisces, Erythrinidae) de diferentes bacias hidrográficas do Brasil. MSc Dissertation. Universidade Federal de São Carlos, Brazil.

- and Bertollo, L. A. C. 1988. Karyotype variability in Hoplerythrinus unitaeniatus (Characiformes, Erythrinidae). I. Chromosome polymorphism in the rio Negro population (Manaus, State of Amazonas). Brazil. J. Genet. 11: 299-306.

- and - 1990. Karyotypic variability in Hoplerythrinus unitaeniatus (Pisces, Characiformes, Erythrinidae). II. Occurrence of natural triploidy. Brazil. J. Genet. 13: 231-237.

Godoy, M. P. 1975. A Família Erythrinidae. In: Peixes do Brasil, Sub Ordem Characoidei. Bacia do Rio Mogi Guassu. V.3. Editora Franciscana, Piracicaba. pp. 440-444.

Molina, W. F. and Bertollo, L. A. C. 1993. Cromossomos sexuais em Erythrinus erythrinus (Pisces, Erythrinidae). XXIV Congreso Argentino de Génetica. Misiones, Argentina. p. 126.

Morelli, S. 1998. Citogenética evolutiva em espécies do gênero Hoplias, grupo lacerdae. Macroestrutura cariotípica, heterocromatina constitutiva e regiões organizadoras de nucléolo. Doctoral Thesis. Universidade Federal de São Carlos, Brazil. 